\title{
PUBLIC HEALTH WORKFORCE: RESULTS OF A NSW STATEWIDE CONSULTATION ON THE DEVELOPMENT OF THE NATIONAL PUBLIC HEALTH WORKFORCE
}

Lynne Madden

Manager, Public Health Training and Development Unit NSW Health

\section{Allison Salmon}

Public Health Officer (Drugs and Alcohol)

NSW Public Health Officer Training Program

The National Public Health Partnership (NPHP) was established in 1996 by the Australian Health Ministers. The Partnership Group consists of the Chief Health Officers or the heads of the Public Health Divisions in each State or Territory and the chief executives of the National Health and Medical Research Council and the Australian Institute of Health and Welfare. A representative of the New Zealand Government participates as an observer. The initial focus of the NPHP has been to strengthen the national infrastructure of public health, including the development of the public health workforce. In August-September 1998, the NSW Department of Health, on behalf of the NPHP, undertook a statewide consultation seeking opinions on the development of the national public health workforce. This article describes the consultation process, highlights some of the findings and provides an update on how the NPHP intends to proceed with national public health workforce development.

\section{THE CONSULTATION PROCESS}

The NPHP established a planning group in late 1997 which oversaw: the production of a background paper that summarised recent public health workforce development in Australia; and a discussion paper that clarified some of the current issues in this area and suggested priorities and potential objectives for a national approach to workforce development.

These two documents were distributed to all the States and Territories, who were asked to consult with their public health workforces on the discussion paper. Results of all the consultations were to be used by the planning group to prepare a submission to the NPHP proposing future action on national public health work force development.

The NSW consultation consisted of three components: a request for written feedback, a forum of key stakeholders and a rural teleconference. The NSW Department of Health requested written feedback from public health groups within the health and academic sectors who were expected to be interested in the development of the public health workforce. Included were:

- branches within the Public Health and Policy Divisions of the Department of Health
- Divisions of Population Health

- professional groups, such as Public Health Unit directors, public health nurses, environmental health officers, and health promotion workers

- local health service special interest groups, such as the Epidemiology Special Interest Group

- academic groups, such as the Department of Public Health and Community Medicine at the University of Sydney

- bodies representing public health professionals, such as the NSW Branch of the Public Health Association

- non-government organisations, e.g. the National Heart Foundation

- members of the NSW Department of Health's Public Health Workforce Development Committee

- rural representatives of many of the preceding organisations

- professional bodies representative of general practice.

Representatives of these groups were invited to participate in a forum to discuss: themes emerging from the written responses; perceived gaps in the public health workforce in NSW; and examples of successful workforce development initiatives. While there was some rural representation at the forum, a teleconference was organised to seek the opinions of a number of rural representatives who were unable to attend.

\section{RESULTS OF THE CONSULTATION}

Respondents felt that the NPHP is well positioned to take a strategic view across the many services and academic structures that contribute to public health work and workforce development in Australia. There was also consistent and strong support for linking education and practice in public health training. Of the many themes that emerged from the process, we have selected four to profile here:

- core knowledge and skills shared by the public health workforce

- types of public health workers

- learning organisations

- rural public health workforce.

Core knowledge and skills shared by the public health workforce

There was a consensus regarding the need to articulate the specialised knowledge and skills required by the public health workforce. It was recognised that these skills are usually held at different levels of sophistication depending upon the responsibilities of the position and, consequently, that training should be directed at achieving 
an appropriate level of skill. Figure 1 lists the knowledge and skills suggested by the consultation as core to public health work.

\section{Types of public health worker}

Three broad types of public health worker were identified, each with particular combinations of knowledge and skills: generalist public health workers, specialist public

\section{FIGURE 1}

CORE KNOWLEDGE AND SKILLS NECESSARY FOR PUBLIC HEALTH WORK

- Management skills, including management of change, resource management and organisational development

- Service planning

- Intersectorial working

- Whole-of-government approaches

- Team building

- Community consultation/community planning

- Communication and negotiation

- Establishing and maintaining information technology skills to support e-mail and Internet access

- Maintenance of data sets

- Descriptive epidemiology and surveillance

- Infectious diseases

- Evidence-based practice

- Program/service evaluation

- Intervention designs

- Health promotion

\section{FIGURE2}

\section{ORGANISATIONALINFRASTRUCTURE AND} WORKFORCE DEVELOPMENT

Appropriate physical infrastructure

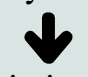

Job descriptions and roles

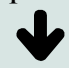

Skills and knowledge

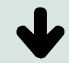

Organisational support promoting change, including adequate resources health workers and health workers who have a public health component embedded within their professional practice.

Generalist public health workers are required to take a broad perspective of issues and are usually found in positions where resources or organisational structure demand multiple skills. Examples ranged from many public health service management positions to workers in areas of social need (e.g. drug and alcohol) and rural areas.

Specialist public health workers have knowledge or skills pertaining to either a particular area or setting or a higher level of skill than generalist workers. Examples included epidemiologists, health promotion workers and environmental health officers.

The third type is health workers who have a public health component embedded within their professional practice. There was agreement that most health workers required some public health knowledge and skills to be effective. For example, those in active clinical practice should have an understanding of evidence-based health care. The Royal Australian College of General Practitioners has recognised this need and has recently included population health in their training for general practice. Population Health Needs and Priorities is one of three dimensions used to develop their new curriculum.

\section{Learning organisations}

Many respondents emphasised that workforce development is seldom achieved effectively in isolation from broader organisational concerns. They felt that to be effective workforce development needs to be integrated into the overall development of an organisation and its goals, a concept embodied by the term 'learning organisations'. In other words, learning that is system wide focuses not only on the needs of the individual, but also on the needs of the whole organisation. Figure 2 suggests a model that acknowledges the impact of the physical infrastructure of the organisation on workforce development.

\section{Rural public health workforce}

The rural public health workforce was identified as having a particular need for development. This group encompasses multi-skilled clinical and community health workers who usually undertake a wider range of activities than their colleagues in metropolitan areas. Because it can be difficult to recruit highly skilled specialists to rural areas, development of the existing work force is essential. Skills in data collection and the organisational aspects of public health surveillance were cited as areas in which further training is needed. 


\section{OUTCOME FROM THE NATIONAL CONSULTATION PROCESS}

The NPHP executive prepared a final report that was forwarded to the NPHP for their consideration in November 1998. At that meeting, a number of priority areas were agreed upon, including health promotion, leadership skills and environmental health (particularly environmental toxicology). An infrastructure project to examine the monitoring and planning of the public health workforce and to identify core public health workforce disciplines was also supported. The original planning group has now been disbanded and the next phase will be taken forward by a number of different groups. The Bulletin will continue to report on the outcomes of this work.
A paper summarising the results of the NSW consultation and including copies of the workforce documents produced by the NPHP was published by NSW Health in December 1998. The document, NSW Consultation on the Development of the National Public Health Workforce for the National Public Health Partnership, is available on the Public Health website at www.health.nsw.gov.au/public-health/nphw.

8

\section{NEW SUBSCRIBERS / CHANGE OF ADDRESS FORM}

Cut or copy this page and mail or fax to:

The Editor

NSW Public Health Bulletin

Locked Mail Bag 961

North Sydney NSW 2059

Fax: (02) 93919232

[ ] I wish to be placed on the mailing list

[ ] Please remove me from the mailing list

[ ] I wish to change my mailing details, as follows:

Name:

Organisation:

Mailing address:

State:

Telephone:

Email:
Postcode:

Facsimile:

The Bulletin can be accessed via the Internet from our Web site at www.health.nsw.gov.au/public-health/phb/ phb.html. If you would like to be informed by email when new editions of the Bulletin become available, please subscribe to the Internet mailing list when you next visit the site. 